\title{
Ambient scent as a mood inducer in supermarkets: The role of scent intensity and time-pressure of shoppers
}

\section{Leenders, MAAM}

http://hdl.handle.net/10026.1/5220

\subsection{6/j.jretconser.2016.05.007 \\ Journal of Retailing and Consumer Services}

All content in PEARL is protected by copyright law. Author manuscripts are made available in accordance with publisher policies. Please cite only the published version using the details provided on the item record or document. In the absence of an open licence (e.g. Creative Commons), permissions for further reuse of content should be sought from the publisher or author. 


\title{
Ambient Scent as a Mood Inducer in Supermarkets: The Role of Scent Intensity and Time-Pressure of Shoppers
}

\author{
Authors: Mark AAM Leenders, Ale Smidts, and Anouar El-Haji. \\ Forthcoming in Journal of Retailing and Consumer Services.
}

\begin{abstract}
This research aims to study the effect of a carefully selected congruent and simple ambient scent in a real-world supermarket setting. Specifically, we study how different levels of scent intensity affect shopper's mood, behavior and evaluations in a space with naturally occurring scents. Using electrostatic aroma diffusers, we apply a carefully selected melon scent at three different intensity levels in a large store of a major supermarket operator. The results show that, in the condition with high scent intensity, the scent has a significant positive effect on shopper's store evaluations, time spent in store and store level sales. We provide evidence that mood is, as expected, a strong mediator of the effect of scent on positive evaluations. We also find that scent, used as a mood inducer, is especially effective for hurried shoppers. Interestingly, in terms of general mood inducement, we find that shoppers tend to overestimate the amount of time spent shopping at lower intensity levels and underestimate time spent shopping at high scent intensity levels. Implications for marketing and store management are discussed.
\end{abstract}

Keywords: Ambient scent, supermarket, time pressure, field experiment, shopper behavior 


\section{Introduction}

Managers in a broad range of industries are increasingly paying attention to the atmosphere in the space where customers interact with their products and services. In this respect, color, temperature, lighting and music are obvious environmental factors that have been shown to influence the perceived attractiveness of the service environment, product and store evaluations, customer satisfaction and sales (Babin and Attaway, 2000; Baker et al., 1994, 2002; Donovan et al., 1994; Doucé and Janssens, 2013; Hermman et al., 2013; Labrecque and Milne, 2012; Morrison et al., 2011; Turley and Milliman, 2000; Turley and Chebat, 2002).

One environmental factor that has received only scant attention in the marketing literature is ambient scent (Achrol and Kotler, 2012; Goldkuhl and Styvén, 2007; Morrison et al., 2011; Spangenberg et al., 1996; Spence et al., 2014; Teller and Dennis, 2011). Using technologically advanced scent conditioning systems, natural or artificial substances are released in the ambient environment of homes, hotels, casinos, healthcare institutions and retail stores (Chebat and Michon, 2003). Examples of such places are the Mirage in Las Vegas, the Marriott airport hotels in Miami, the Magna Plaza shopping mall in Amsterdam, and most entertainment parks in Orlando Florida. Managers are also increasingly using ambient scent in a broad range of retail stores (Bradford and Desrochers, 2009; Parsons and Conroy, 2006). For example, the Burberry stores in London are using custom made scents to add to the customer experience and brand recognition (Allsens, 2012) and according to Peltier (1998), president of AromaSys, his company alone developed aroma diffusion systems for over nine hundred retail stores in the U.S.

Over the years, a small but slowly growing number of academic studies have documented a range of effects of ambient scent in marketing environments (Teller and Dennis, 2011). In retailing, for example, field tests suggest that a pleasant ambient scent may 
increase the time spent in the store (Knasko, 1995; Teerling et al., 1992), lead to better evaluations of the store and its merchandize (Lwin and Morrin, 2012; Michon et al., 2005) and increase the money spent (Hirsch, 1995). Other laboratory studies report similar effects (e.g., Spangenberg et al., 1996). However, there are also studies that found mixed or no measurable effect of ambient scent (Fiore et al., 2000; Teller and Dennis, 2011).

Hermann et al. (2013) show that scent composition plays an important role in the effects it generates. Its complexity, for example, affects the cognitive processing of the scent. Their findings suggest that the composition of the scent may explain why scent has had a positive effect on shopping behavior in some studies and not in others: scent composition and complexity. This goes back to the notion of scent congruency, which is known to affect cognitive processing (Cirrincione, Estes and Carù, 2014; Doucé et al., in press). Shoppers may be more likely to process cues rationally instead of emotionally if the scent is not congruent (Bone and Ellen, 1999). For example, shoppers may start elaborating where the scent is coming from and what causes it. This is consistent with the elaboration likelihood model (ELM) that argues that if the elaboration is high, a person's cognitive responses will largely determine the behavioral outcome. If the elaboration is low, shoppers are less likely to engage in cognitive processing and emotional effects are more likely to occur (Petty and Cacioppo, 1986; Vinitzky and Mazursky, 2011). As a result, it is clear that any study of the effects of ambient scent should provide a detailed description of the scent itself, the targeted effect(s) and the type of environment in which the scent is applied. The same scent applied in a music club may have different effects in a grocery store because of different mechanisms.

Past studies have been conducted in a diversity of settings such as laboratories, malls, clothing stores and clubs and used different reasoning for selecting a specific scent (see Table 1). Furthermore, the scent type varies considerably across studies and it is not always made 
explicit whether the scent is supposed to be congruent with the product, environment or other variables.

\section{---- TABLE 1 ----}

In this study the focus is on mood effects as a mechanism by which scent can affect consumer behavior. Consistent with scholarly discussions, we use the term mood to describe an internal feeling state (Garnder, 1985) in contrast to, for example, more cognitive processes. For ambient scent to have a relatively isolated mood effect, the fragrance and the mental representation of the environment stored as cognitive schema need to be carefully aligned (Knasko, 1995; Matilla and Wirtz, 2001). Fiore et al. (2000), for example, find effects of ambient scent on different mood components if the scent is appropriate for the retail situation and product assortment. Indeed, environment congruence may occur when the environment or merchandize naturally emits odors and the added artificial scent is perceived to be congruent with the natural scents. Natural scents are often present in a bakery, meat shop, perfume store and garden center. Congruency can then be achieved by using a scent that fits well and blends in with the overall store aromas.

A second factor that may influence consumer reactions to ambient scent is the scent intensity level. Generally not much is known about scent intensity yet except for that the intensity should not be too high, because even pleasant scents become unpleasant if the intensity is too high (Richardson and Zucco, 1989). Earlier ambient scent studies do not explicitly study the effect of different intensity levels even though they might have calibrated the intensity level to ensure, for example, that it is at the threshold level (e.g., Doucé en Janssens, 2011). Most previous studies compare between scent and no scent treatments (e.g., Michon et al., 2005), and may add different type of scents (e.g., Matilla and Wirtz, 2001). 
In our study we therefore manipulate the scent intensity level to study its effects on consumers. Here, we expect that individual differences will moderate the effects of intensity. Shoppers are known to differ in their sensitivity to scent due to, for example, gender because on average women are more sensitive to scent than men (Cain, 1982), and age as sensitivity decreases with age (Doty et al., 1984). More importantly, responsiveness to a scent may be different for different types of shoppers. That is, some shoppers, for example, may already be in a good mood and if the scent is used to have a positive effect on mood, the desired effects may be limited. Other shoppers can be in a relatively bad mood. Time pressure, for example, is a prominent cause of shopping stress (Aylott and Mitchell, 1999) and time pressure may affect mood negatively and lead to less favorable product evaluations (Masayo et al., 2007). In this study, it is argued that ambient scent might alleviate the detrimental effect of time pressure on mood and shopping behaviour (Baron and Bronfen, 1994) and thus enhance customer evaluation and approach behaviour, such as unplanned purchases that is known to be higher if perceived time pressure is lower (Turley and Milliman, 2000).

In sum, the aim of this study is twofold. Firstly, we test the effects of a pleasant and congruent ambient scent at different intensity levels in a real supermarket on shoppers' mood and their evaluations and in-store behaviors. To the best of our knowledge, no real-world experiment in a rich aroma environment, such as supermarkets, has yet been published. Through close cooperation with store managers, scent experts from the food industry, and by using the latest diffusion technology we implement specific diffusion strategies and test them in terms of effectiveness in a supermarket context. Congruency between the expert selected simple scent and the environment is considered important to elicit predominantly a mood effect (Mattila and Wirtz, 2001; Schifferstein et al., 2011). Secondly, we explore the moderating effects of shopper characteristics such as age and gender, and we test whether the 
detrimental effects of a shopper's time pressure can be alleviated by the application of a congruent ambient scent.

\section{Theoretical Background}

Although the number of applications of ambient scent is rising fast in many industries and much is known about the effects of odors on human physiology and psychology, the number of studies on the effects of ambient scents in specific marketing and retailing contexts is still scant (Chebat and Michon, 2003; Teller and Dennis 2011). Up till now, select studies have been conducted in laboratory or field settings such as jewelry stores (Knasko, 1989), sports equipment stores (Stöhr, 1998), clothing stores (Teerling et al., 1992; Hermman et al., 2013), gift shops (Matilla, 2001), community shopping malls (Michon et al., 2005) and casinos (Hirsch, 1995). Many laboratory studies take place in neutral rooms, where a scent is introduced to establish its effects (e.g., McCaffrey et al., 2009; Moore, 2014)

The retail environment, in general, has been found to influence shopping behavior (Turley and Milliman, 2000). With respect to ambient scent, classical studies such as Spangenberg et al. (1996) found that a pleasant scent improved store evaluations. A further interesting finding in their study was that subjects exposed to scent appeared to underestimate the time spent in the store, whereas subjects in the no-scent condition overestimated the time spent, thus suggesting a cognitive mechanism for the improved store evaluation. Stöhr (1998) studied the effect of ambient scent on customers' affect and their perceptions of the shopping environment. She conducted a field experiment with a citrus scent in a specialty store of sports equipment. The facial expression of the customers and time spent in the store were observed. At the end of the shopping trip interviews were conducted and her results showed that ambient scent had a strong effect on mood. Also, ambient scent positively affected intention to return to the store (approach behavior) and evaluation of the merchandize. 
Significant positive effects of scent were also found on the observed mimic of customers (i.e., more smiling faces) and on the objective time spent in the store. Unfortunately, the impact of positive affect on store evaluations and behavior of customers was not studied.

An early field experiment in a jewelry store showed no effect on dollar amount spent even though scented areas affected time spent in the store (Knasko, 1989). In a field experiment in a Las Vegas Casino, Hirsch (1995) found that ambient scent can increase the amounts of money gambled at slot machines. Also, Morrin and Ratneshwar (2000) showed that the presence of a pleasant ambient scent improved brand evaluations, especially for unfamiliar brands. Also, recall for brand names improved for unfamiliar brands.

The careful selection and application of ambient scent seems to play an important role in establishing desired effects. Spangenberg et al. (1996) found that the specific type of scent applied did not matter much, as long as the scent was perceived as neutral to pleasant. Other studies have indicated that the congruency with the shopping environment is important. In a simulated shopping environment, Mitchell et al. (1995) found that odor that is congruent with the product class, had a positive effect on the quality of consumer decision making by spending more time processing the different options. In a field study in a gift shop, Mattila and Wirtz (2001) found that congruency between ambient stimuli was important. Matching the arousing nature of the scent (relaxing or arousing) and the background music (slow or fast tempo) resulted in more satisfaction with service and self-reported approach and impulse buying behavior. Effects on behavior were not studied. Also, the precise intensity level is not known. Unfortunately, as stated in the introduction, not much is known about the actual intensity in most studies in general as often only a broad description of its intensity is presented (e.g., Morisson et al., 2011).

An important question that has received some attention in the literature is how the effects of ambient scent come about. Several studies in the area of environmental psychology 
presume a mediating effect of mood. However, in the area of ambient scent, attention has also been given to more cognitive effects of scent (e.g., Chebat and Michan, 2003). Chebat and Michon (2003) even found that a cognitive theory of emotions better explains the effect of ambient scent. On the other hand, Spies et al. (1997) found that customer's mood at least partially mediated the effect of store atmosphere. Regarding the effect of scent on mood, more definite findings have been reported. The meta-analysis of Bone and Ellen (1999) provided support that pleasant scents positively affect mood. Also, Stöhr (1998) found that scent indeed had a positive effect on customer's mood. More recently, Lehrner et al. (2005) provide evidence that ambient scent can reduce anxiety and improve mood significantly.

In sum, the literature on ambient scent in shopping contexts suggests that pleasant and congruent scents may positively affect brand and product evaluations and buying behavior by mediating mood or cognitive processing. However, there is a lack of studies that focus on intensity level and how the scent intensity is moderated by shopper characteristics (e.g., Fiore et al., 2000).

\section{The Conceptual Model}

Figure 1 presents a visual representation of the impact of an ambient scent on customer evaluations and their behavior. This conceptual model builds upon the well-known servicescape model of Bitner (1992). Bitner's model originated from the Mehrabian-Russell (1974) environmental psychology model (Donovan and Rossiter, 1982; Donovan et al., 1994; Zeithaml and Bitner, 1996). Essentially, in Figure 1 an environmental feature, in this study ambient scent, is related to the customer's evaluations of and behavior in the environment, mediated by the customer's emotional state (affect) created by the environment. Time pressure is hypothesized to moderate the effect of ambient scent on store and merchandize 
evaluation and approach behavior. Finally, specific shopper characteristics such as age may moderate the relationship as well if there is sufficient variation in the shopper population.

\section{---- FIGURE 1 ----}

In line with previous studies of store atmosphere (e.g., Spangenberg et al., 1996), the impact of scent is studied with respect to evaluations and approach behavior in particular. Evaluations are differentiated into evaluations of: (a) the store in general, (b) the store environment, and (c) the merchandize. With respect to approach behavior, we distinguish: (a) the actual time spent in the store, (b) the perceived time spent in the store and (c) the extent of unplanned purchasing.

\section{The Role of Mood}

Our main theoretical underpinning of the effect on evaluations and behavior comes from Mehrabian and Russell's (1974) classical approach-avoidance behavior theory in which mood is a mediating factor between environmental cues and evaluations and behavior. A pleasant and congruent ambient scent is thought to improve mood and influence subsequent evaluations and behavior in a mood-congruent direction. Since we use a pleasant and congruent scent in a shopping situation with a considerable proportion of shoppers with an existing positive mood, one may expect emotional states to surface as a mediator between scent and evaluations and behavior (Donovan and Rossiter, 1982; Doucé en Janssens, 2013; Teller and Dennis, 2011). Evaluations and behavior have been shown to be influenced in mood congruent directions (Gardner, 1985).

H1: A customer's mood mediates the positive impact of a pleasant and 
congruent ambient scent in a supermarket on evaluations and approach behavior.

\section{The Effects of Scent Intensity}

The availability of new technology (i.e., electrostatic liquid vaporization systems) makes it possible to increase the control of the scent exposure (Peltier, 1998). Surprisingly, intensity of scent has not been studied well in the context of ambient scent in retail settings. Most studies refer to a "clearly noticeable scent" (Baron and Bronfen, 1994), which means the scent is above the threshold level of perception. For example, Mattilla and Wirtz (2001) mention that the "scent [is] at the appropriate level" and at the "appropriate intensity." Another example is Knasko (1992) who only mentions that the scent is of "moderate intensity." In one field experiment, scent was purposively kept around the threshold level of perception (Teerling et al., 1992). They report positive effects on the time spent in the textiledepartment stores, indicating that even scent at the threshold level may still have a positive effect. Stöhr (1998) indicates that the optimal intensity would be just above the threshold level of perception.

To the best of our knowledge, only in the simulated shopping experiment by Spangenberg et al. (1996) the effect of different levels of scent was studied. However, even their lowest scent intensity level seems to be at the suprathreshold level, which may explain why they were unable to find any measurable effects of intensity. With respect to the intensity of odor, we note that it is sometimes advised to use scent on the threshold level of perception (Peltier, 1998) as high concentrations of scent may cause negative reactions (Richardson and Zucco, 1989). Even pleasant scents become unpleasant if the intensity is too high. Spangenberg et al. (1996) inferred from optimal arousal theory that the relationship between intensity and liking may follow an inverted U-shaped function for pleasant scents. In 
addition, more intense levels of scent may cause more cognitive processing, especially if the scent is less congruent with the environment. As a result, most researchers seem to focus on 'moderate' scent intensity levels that seem at least at suprathreshold level, which ignores more extreme values that may have an effect on liking according to the optimal arousal theory. For example, Morrin and Ratneshwar (2000) found that 58\% of the exposed subjects reported to have smelled the scent in the room, and thus it can be classified as a study around the threshold level of perception.

In retail conditions ambient scent is only one of many environmental influences on the consumer. One may hypothesize that scent has to be above the threshold level in order to have an impact in field settings. Engen (1991, p. 52) states that one cannot expect effects of scent on behavior at the threshold level of perception. Also, the threshold levels of perception differ between consumers (e.g., females smell better than men). Thus, one requires an intensity level that is noticed by a majority of the customers in a store. The results of Hirsch (1995) indeed suggest that in a very distracting environment, such as a casino, higher levels of odor may be required before effects set in. Of course, care should be taken to preclude detrimental effects because of too high concentrations. Since managers of retail outlets have to decide on the aroma level, we test whether the intensity of ambient scent affects evaluations and behavior. We propose that

H2: $\quad$ The positive effect of a pleasant and congruent ambient scent in a supermarket on evaluations and approach behavior increases with the scent intensity level, on the condition that the scent level is still experienced as pleasant. 


\section{The Effects of Time Pressure}

A second issue we study concerns the moderating role of time pressure. From a marketing perspective, the use of scent would be very advantageous if it would be able to counteract negative effects of stress caused by time pressure. Many such negative effects of timepressure on mood have been reported (Park et al., 1989). Consequently, their mood would negatively influence buying behavior (Herrington and Capella, 1995).

Time pressure influences the effect of scent. In particular, one may hypothesize that customers shopping under time pressure are affected less strongly by scent than customers not under time pressure. In general, customers experiencing moderate to high time pressure will enter the store in a more negative mood than customers in a low stress condition (Baron and Bronfen, 1994). Such a negative mood would result in less positive evaluations of the store and its merchandize. The incompatible response hypothesis (Baron, 1978, 1993) predicts that negative mood states (such as frustration or anger) can be reduced by exposure to stimuli or conditions serving to induce reactions incompatible with such feelings. Exposing customers in a more negative mood to pleasant scents thus would induce increments in positive affect. Pleasant scents might therefore serve to counter negative reactions associated with stress. Customers that are fairly relaxed and in a positive mood, would benefit less from pleasant scents than customers that are more stressed. If mood indeed mediates the effect of scent on evaluations and behavior (H1), we consequently propose that the effect of a congruent and pleasant scent on evaluations and behavior is larger for stressed customers than for relaxed customers. 
H3: $\quad$ The positive effect of a pleasant and congruent ambient scent in a supermarket on evaluations and approach behavior will be stronger for time-pressured customers than for relaxed customers.

Apart from situational characteristics, it is well documented that there are wide differences among individuals in sensitivity to odors (Lawless, 1997). In general, females smell better than males and scent detection decreases fairly rapidly with age. More than half of elderly between the age of 60 and 80 show signs of major olfactory impairment (Doty et al., 1984). Consequently, young and middle-aged shoppers are perhaps influenced more strongly than the adults with an age above 65, and female shoppers may be affected more than male shoppers. As retail stores may differ regarding characteristics of their customers, the potential benefits of applying ambient scent may well depend on their customer base and this will be analyzed as well.

\section{Method}

\section{Field experiment}

A field experiment was conducted in a supermarket store of one of the major supermarket chains in the world. The experiment was conducted in close cooperation with a company specializing in applying aroma technology in retail environments. In a between-subjects design, data were collected in multiple weeks by means of a questionnaire and observation of objective time spent in the store. The store is an example of the retail chain's 'third generation concept', entailing a high quality and modern interior in which shelves are positioned low on islands thereby creating a spacious atmosphere.

The experimental variable in the study is the intensity level of a carefully selected pleasant ambient scent. A professional scent panel rated several readily available scents in the 
categories floral, spices, and citrus on safety, pleasantness, and suitability in a supermarket's environment. Also simplicity and handling safety in a real world supermarket were considered. For example, management was worried about costs and possible spill danger. In the end, a melon scent from the citrus category was judged to be most appropriate fitting well with natural aroma's one would find in a supermarket. Other characteristics of the selected scent are that it is safe, easily synthesized and therefore not expensive to use and that it is known to be 'universally liked' according to experts. Considerable attention was paid to the aroma distribution technique and the preferred locations of the devices. We applied the electrostatic vapor distribution using non-liquid granulate filling. This technique has the advantage that the intensity level of scent can be accurately tuned and that the risks of spills are low. The devices were invisible to customers and positioned in the first half of the store that includes the area for fresh produce, and near the entrance and cash registers resulting in a natural flow throughout the store. We thus accomplished a safe and controlled emission of pleasant scent using devices invisible to customers.

The three experimental conditions are: (1) no ambient scent (control condition), (2) scent at the threshold level (50\% intensity), (3) and scent at the suprathreshold level (70\% intensity). An extensive pre-test method was used to calibrate the intensity level in the store based on how the devices' settings and emitted scent worked out in the actual store. A level of $50 \%(70 \%)$ is defined as the condition in which $50 \%(70 \%)$ of a group of regular shoppers was able to recognize the scent in the store (Doty, 1991, p. 102, Nixdorf et al., 1992). A pretest sample of shoppers ( $n=25$ per condition) were asked to make a short store trip in the store of study. After the trip, two questions were asked: "Did you smell something different from usual?" and "What did you smell?" Respondents had to respond positively to the first question and answer with 'fresh' or 'fruit like' to the second in order to count as an ambient 
scent recognition. This procedure is commonly used by olfactory experts in field applications (Nixdorf et al., 1992).

\section{Data collection and sampling}

In order to get experimental conditions that are maximally comparable with respect to external variables (i.e., shopper characteristics, number of shoppers, shopping goals and store level sales), we selected days that showed the least between-weeks variance in these respects. Internal data of the supermarket showed that Tuesdays and Wednesdays are most strongly comparable, both within and between weeks. Furthermore, both weekdays are treated as a block because, due to the lingering quality of scent, it is not advised to allocate different scent conditions to consecutive days as the independence of conditions cannot be guaranteed. The experimental conditions were allocated randomly to three weeks. It was made sure that the experimental conditions did not differ with respect to marketing variables, such as in-store sales promotions or communications. The study was conducted during daytime on six days in a period of three consecutive weeks. The selection of similar weeks was done using insights from store management, historical sales and customer records.

A random sample of shoppers was drawn during daytime opening hours by means of a systematic sampling procedure of arriving adults. In order to assess the actual time spent in the store, observers registered the arrival time of the potential respondent. When the observed respondent arrived at the checkout counter queue, the end time of the trip was registered. Upon leaving the shop, observed customers were intercepted and asked to participate in a study on the evaluation of the supermarket and to fill out a four questionnaire for which special facilities (e.g., tables and pencils) were available at a location nearby and out of sight of arriving customers. Before the interception, there was no interference with the regular shopping trip of the customer. The self-administered questionnaire was in Dutch and 
extensively pre-tested among academics and supermarket shoppers regarding the questionnaire's design, length and wording. Since the items come from mostly English language scales and studies, we used translation and reverse translation to develop equivalent Dutch questions. A copy of the Dutch questionnaire can be obtained from the authors.

Overall, $66 \%$ of observed customers were willing to participate. For each experimental condition, data of about 100 shoppers were collected on two days. This resulted in a total sample of 302 respondents. Non-response/ response rates and arrival times of respondents did not significantly differ between the three conditions (Average arrival time is between 1:20 pm and 1:43 pm in the three conditions).

\section{Measures}

Existing measures from the extant literature on mood, consumer behavior, and retail environments (Mehrabian and Russell, 1974; Spangenberg et al., 1996) were used. A complete list of the multi-item scales is presented in Appendix A.

Shopper's mood was measured by means of an eight-item Pleasure Arousal Dominance (PAD) measure on 7-point semantic differential response scales (Mehrabian and Russell, 1974). A confirmatory factor analysis (Steenkamp and van Trijp, 1991) showed that this scale consisted of three strongly correlated dimensions related to pleasure, arousal, and dominance $\left(\chi^{2}(17)=37.27, p=.003, \mathrm{RMSEA}=.065 ; \mathrm{TLI}=.97 ; \mathrm{CFI}=.98\right)$. Considering the strong correlations between the components $(r>.86)$, we also constructed one composite scale by averaging the scores over the items (Cronbach $\alpha=.91$ ). Analyses will be conducted both on the composite and the component scales to check for differences across sub-dimensions.

The overall evaluation of the store was measured with regard to the store in general (bad to good), store quality (low to high), and the customer's satisfaction with the store (low to high) all on 10-point scales. This response scale was used because people in the country of 
research are familiar with providing overall grades on a 10-point sale. Factor analysis revealed one underlying dimension. A composite scale was formed by averaging the scores on the items (Cronbach $\alpha=.87$ )

The evaluation of store environment was assessed by means of five 7-point semantic differential scales such as pleasantness and openness (Spangenberg et al., 1996). Factor analysis revealed one underlying dimension. A composite scale was formed by averaging the items (Cronbach $\alpha=.77)$.

Three items were used to measure a shopper's evaluation of the store's merchandize on 7-point semantic differential scales. In our operationalization we focus on the evaluation of fresh merchandize: fruit and vegetables, butchery products and bakery products, because these categories play a prominent role in the assortment and revenues of supermarkets and because management was especially interested in whether scent could further support the fresh categories. Factor analysis revealed one underlying dimension. A composite scale was formed by averaging the item scores (Cronbach $\alpha=.73$ ).

Confirmatory Factor Analysis (CFA) with three indicators for pleasure, three indicators for arousal, two indicators for dominance, three indicators for the general store evaluation, five indicators for the evaluation of the environment, and three indicators for the evaluation of the merchandize resulted in a satisfactory fit $\left(\chi^{2}(137)=284.9\right.$, RMSEA $=.062$, GFI $=.91$, TLI $=.94$, CFI $=.95$ ). Discriminant validity was examined by calculating the confidence intervals around the inter-factor correlations ( $\phi$ 's). Since none of the intervals did contain a value of 1 and because setting a value to 1 resulted in poor fitting models, we conclude that the constructs possess good discriminant validity.

With respect to approach behavior, the actual time spent in the store was calculated from the observed arrival time and the end time of the shopping trip (until queuing). The perceived time spent was assessed by asking shoppers to provide an estimate of the time in minutes 
they had spent in the store, reckoned from entering the store until arriving at the checkout queue. By comparing the subjective estimate to the actual time spent in the store, the amount of overestimation was calculated. Unplanned purchasing behavior was assessed by a single item, which consist of asking customers whether they had bought less, the same or more than planned. Finally, the store records provided data on the daily number of shoppers and daily store level revenues and this daily store data will be included in the analysis as well.

The time-pressure experienced was measured by means of a 7-point scale ranging from 1 'not in a hurry' to 7 'very much in a hurry'. To check the scent manipulation, we assessed the perceived pleasantness of the smell in the store on a 7-point scale ranging from 1 'unpleasant' to 7 'pleasant'. This was the final question before the demographics section such that subjects were unaware of the research topic.

\section{Results}

\section{Manipulation check}

Shoppers in different scent conditions rate the pleasantness of the smell in the store differently $(F=3.20, p=.04)$. In the suprathreshold condition the pleasantness of the odor was rated significantly more pleasant $(M=5.9)$ than in the control $(M=5.5)$ or threshold condition $(M=5.4)$. No significant difference was found between the control and the threshold condition. In all conditions the scent was rated as pleasant given that the average scores are significantly higher than the mid-point of the response scale $\left(X_{\text {mid-point }}=4, p\right.$ $<.001)$. Less than $2 \%$ of the respondents rated the scent below the mid-point. We thus achieved the necessary condition that a neutral to pleasant scent is required to obtain positive atmospheric effects (Spangenberg et al., 1996).

There are no major differences between the experimental conditions other than the scent diffusion. The conditions are similar with respect to the average arrival time of the shoppers 
$(p=.39)$ and arrival time distribution (paired K-S tests, $p>.10)$, party size $(p=.70)$, age $(p$ $=.82)$, the percentage of primary shoppers $(p=.42)$, the frequency with which the shopper visits the store $(p=.88)$ and the experienced time-pressure $(p=.43)$. We did find a small difference in the percentage of female respondents in the three conditions (control: $75 \%$, threshold: $82 \%$, suprathreshold: $91 \%, p<.02)$. We control for this difference in all subsequent analyses. Finally, the store records showed that the total number of customers that visited the shop in each experimental condition was highly similar with less than $2 \%$ difference in the total number of daily visitors across all conditions. We conclude that the experimental conditions are very similar with respect to shopper characteristics and store traffic. This confirms that the selection of weeks and days of the experiment was appropriate for properly testing the impact of the ambient scent manipulation.

---- TABLE 2 ----

\section{Effects on evaluations and behavior}

The experimental effects of scent on the dependent variables are presented in Table 2. As hypothesized, there is a positive effect of scent on the dependent variables (MANOVA, Wilks' lambda $=.887, F=2.73, p=.001, n=274)$. The follow-up tests of all pair-wise comparisons indicate that effects predominantly and significantly show-up in the suprathreshold condition. No significant effect of the threshold condition emerges, although there is a tendency towards a positive effect relative to the control situation. Unintended purchases are significantly higher in the suprathreshold level (43\% compared to $33 \%$ and $30 \% ; F=4.24, p=.06$ ). 
Scent appears to result in longer shopping trips, especially at the suprathreshold level (see Figure 2). Interestingly, the increase in the actual time spent is not subjectively experienced as such. Shoppers overestimate the time spent in the store in the no scent and threshold condition and underestimate the time spent in shop in the suprathreshold condition (see Figure 2). These differences between the actual time in store and perceived time in store are significantly different across conditions and higher scent levels lead to shorter trip perceptions $(F=4.24, p=.015)$.

Store level data obtained from management also shows that the scent is associated with higher sales. The financial records indicated an increase in the total amount of money spent in the store during the 'scent days' of the experiment, particularly in the suprathreshold condition: control $=100$, threshold $=102.26$, suprathreshold $=113.84$. Table 2 shows that this may be due to a significantly higher incidence of unplanned purchasing.

In sum, our results suggest that the intensity of ambient scent needs to be sufficiently strong in order to accomplish measurable effects on evaluations and behavior in the store. The results partially confirm Hypothesis 2 .

\section{The mediating role of mood}

As proposed in the model, mood is thought to mediate the effect of scent on evaluations and behavior. To establish mediation, we first have to show that scent affects mood. The first row in Table 2 shows indeed a significant positive effect of ambient scent on affect, especially with respect to the suprathreshold level. Additional analyses on the three subcomponents of mood resulted in a similar conclusion (MANOVA, $F=2.42, p=.026)$ with the largest effect showing up for the arousal dimension $(F=7.72, p=.002)$. Shoppers are particularly more relaxed by our scent, which is in line with the relaxing properties of the scent category (e.g., Spangenberg et al., 1996; Laing et al., 1991, p. 373). 
To further support a mediator role of mood, the effect of scent has to decrease or disappear when the mediator is controlled for (Baron and Kenny, 1986). Table 3A provides evidence for affect as a mediator between scent intensity and the overall store evaluation. For the overall store, there is a significant effect of the suprathreshold level condition (Step 2, $\beta$ $=.12, p=0.08)$. When affect is entered into the subsequent regression, the effect of the suprathreshold condition disappears completely (Step 3, $\beta=.023, p=.72$ ). The same is true for evaluation of store environment and merchandize (see Table 4). These results are further confirmed by means of a simultaneous estimation of the direct and indirect effect using bootstrapping (1000 resamples) and Sobel test (Preacher and Hayes, 2008). For the overall store evaluation, the indirect effect is strongly significant $(z=3.39, p<.001)$, taking over the direct effect of the $70 \%$ condition. Similarly results are found for the store environment $(z=$ $3.66, p<.001)$ and the evaluation of the merchandize $(z=3.37, p<.001)$. We conclude that affect is a perfect mediator of the effects of scent on the full range of store evaluations, supporting Hypothesis 1.

In contrast to the evaluation measures, no mediator effect is found for the behavioral measures. For the objective time spent in store, the effect of the supra threshold level is not explained by better mood state. As Table 3B shows, mood does not significantly affect actual time spent shopping (Step 3, $\beta=.08, p=.18$ ) and the effects of the supra threshold scent condition stays significant (Step 2, $\beta=.255, p<.001$ versus Step 3, $\beta=.215, p=.002$ ). In 
addition, no support for a mediator effect of mood is found on subjective shopping time or overestimation of the time spent in the store (see Table 4). These results are confirmed using bootstrapping with 1000 resamples and a simultaneous estimation of direct and indirect effects with a Sobel test (Preacher and Hayes, 2008). For example, the objective time in store is not mediated by the affect $(z=1.24, p=.21)$ and the direct effect of the supra threshold level stays significant $(t=3.35, p<.001)$.

Since mood appeared to mediate the effect of scent on store evaluations, we also checked whether these store evaluations in turn would explain the behavioral impact of scent. No significant mediating effects were found; the impact of scent on behavior remained unchanged. Both mood and store evaluations resulted only in a slight reduction of the impact of scent. These results suggest that the impact of scent on behavior is more direct and cannot be attributed to changes in mood or changes in store evaluations.

\section{Differential effects of scent on shopper populations}

So far, we did not distinguish between shopper groups in studying the effect of scent. We proposed moderating effects of gender, age, and time-pressure on the relationship between scent and mood. The results show that the interaction effect between scent and sex does not show up (ANOVA, $F=.30, p=.74$ ). No detectable differential sensitivity for scent shows up between males and females. With respect to the moderating role of age, the results are more supportive. Since the medical literature suggests a decline of scent sensitivity at a high age, we first split the sample into two groups with age of 50 as a cutoff. This results in a geriatric group, which is $17.3 \%$ of the whole sample. The interaction between old age and scent 
intensity is significant (ANOVA, $F=3.45, p=.03$ ). The effect of scent on mood is indeed strong for younger respondents and weak to non-existent for elderly. However, given the low number of elderly people, the results should be interpreted with caution.

---- FIGURE 3 ----

The interaction between time pressure and scent on mood is strongly significant $(p=.002)$ and in the predicted direction, thus confirming Hypothesis 3. Figure 3 illustrates the nature of this interaction. For illustrative purposes, a median split on time pressure was applied to distinguish hurried shoppers from less hurried shoppers. The mood of the less hurried shoppers appears to be better in all conditions. Furthermore, the effect of scent intensity on mood is the strongest for shoppers in a hurry. Thus, scent seems to improve the mood of time pressured shoppers more effectively.

Scent seems to offset the generally more negative mood of hurried shoppers and make them stay longer and behave more like unhurried shoppers, significantly increasing shopping times of this group. Even in the threshold level condition, the mood of hurried shoppers is significantly affected. In the supra threshold condition, this effect gets exacerbated, resulting in a substantial effect compared to the no scent condition. Overall, the effect of scent on mood may have been underestimated for the less hurried customer group because of ceiling effects: the less hurried customers are already in a very good mood. Furthermore, this may have led to underestimating time spent and more unplanned purchases.

In a previous analysis, we show that whereas mood did mediate the effect of scent on evaluations, no mediating effect on behavior was found. Considering that the mood of the hurried customers is affected most strongly by scent, one may expect that the role of mood as a mediating factor will be most prominent for the hurried customer group. For this group, 
mood may mediate the effect of scent even for behavior. To test this proposition, we conducted a separate mediator analysis for hurried and less hurried shoppers with respect to objective time spent. The results for hurried shoppers show that mood indeed partially mediates the effect of scent on time spent in the store: Mood significantly affects the time spent $(\beta=.18, p=.068)$, whereas the direct effect of scent in the supra threshold condition reduces from $\beta=.32(p=.003)$ to $\beta=.24(p=.037)$ by inclusion of mood in the regression. For less hurried shoppers, whose mood cannot be boosted substantially, the effect of scent on time spent is relatively small $(\beta=.15, p=.09)$. However, scent only slightly improved mood. This suggests that mood is indeed important in evoking behavioral responses to scent. Interestingly, there seems to be direct effect of scent on behavior remaining that cannot be explained by changes in mood.

For the evaluation of the overall store, we found support for mediating effects of mood for both types of shoppers in the supra threshold condition, although the effect of scent was relatively weak for non-hurried shoppers. For the evaluation of the store environment, we also found that mood was a mediator both for hurried shoppers and for non-hurried shoppers in the supra threshold condition. For the evaluation of the merchandize, we found support for the mediating role of mood. Interestingly, the effect of the threshold condition is significant for hurried shoppers and this effect is not mediated by mood. This may indicate that unconscious effects play a role at this intensity level or that the self-report affect scale cannot detect the underlying mood change. For the objective time spent in store, we found very little support for a mediator effect of mood for both type of shoppers. A very small portion of the effect in the supra threshold condition is generated by mood for hurried shoppers but after correcting for this effect, a strong direct effect of the supra threshold condition remains. We note that this may be related to ceiling effects because the people without time pressure have a very high score on affect already. 


\section{Discussion and Conclusion}

In this study we tested the effects of ambient scent in a real-life retail setting on evaluations and behaviors of customers. Our basic premise is that in order to understand whether and how effects of ambient scents work out in the real world, much more has to be known about how the stimulus is set and how the scent works out in the store atmosphere.

The major conclusion of this study is that scent intensity matters. We only found substantial effects of ambient scent on evaluations and behavior in the supra threshold condition. Only in this condition, customers' evaluations of the overall store, the store environment and the store's merchandize improved. Shoppers in this condition also tended to lose track of time, as they appear to underestimate the time spent in the store. Perhaps even more important is the effect of ambient scent at the supra threshold level on behavioral variables: we found increases in objective time spent in the store, (self-reported) unplanned purchasing behavior and actual purchasing behavior at the store level. By contrast, we were not able to detect significant positive effects on evaluations and approach behavior with scent at the threshold level. Apparently, one has to make the scent stimulus relatively strong in order to 'come through' to a large portion of the shoppers. One cannot hope to find measurable effects with scents at very low levels of intensity such as near threshold level of perception. This is confirmed further by our finding that only in the supra threshold condition, shoppers perceived the odor in the store as significantly more pleasant. The relatively small effect of scent at the threshold condition may be due to the setting that we use, namely a grocery store. In grocery stores, already a variety of (product related) scents is present and our ambient scent may have just homogenized, decreasing the overall evaluation of the pleasantness of the odor. 
Based on the growing literature on the role of ambient scent in retail situations, a positive effect on evaluations and approach behaviors could be expected (e.g., Madzharov, Block and Morrin, 2015). We, however, are the first to show that in field conditions, scent intensity is a crucial managerial variable. The intensity level has to be carefully calibrated in order to get measurable effects on evaluations and behavior. However, a closer look at these studies showed that the role of intensity is remarkably unclear. Whereas the type of scent is usually specified (including a broad typology of the vaporization technology that is used), most studies provide vague descriptions of the intensity level of the scent applied in the study. For one thing, too high levels of intensity lead to unpleasantness regarding scent. But even within the range of pleasant scents, the intensity is a relevant issue that has previously been overlooked that is closely related to the nature and magnitude of the effects that are reported. An intensity level that is often used in practice and the chemical sciences is the threshold level. In our setting, we were able to use this notion of the threshold to deliver two intensities of the scent in a real store: the threshold and supra threshold level.

The studies that have addressed how the effects of scent materialize have often attributed an important role to mood. Our study supports this notion. We found that shoppers in the supra threshold condition were brought into a significantly better mood. In addition, a mediator analysis showed that mood is a perfect mediator for evaluations. A high level of scent intensity is associated with a better mood, and this is associated with better evaluations of the store and its merchandize. However, mood did not mediate approach behavior, which indicates that the effect of scent on approach behavior is more likely to be direct.

The third conclusion of our study is that ambient scent is particularly effective for time-pressured shoppers. That is, to be in a hurry appears to moderate the impact of ambient scent. A pleasant scent appears to improve quite effectively the relatively bad mood of hurried customers. Already at the threshold level, scent appeared to relax hurried customers. 
As mood mediates the evaluations of the store, hurried customers are therefore more positive about the store and its merchandize in the presence of a pleasant scent. Ambient scent also had a positive effect on mood of non-hurried customers. However, since non-hurried customers may already be in a relatively good mood, their mood may be difficult to improve further by means of ambient scent. However, the mood of non-hurried customers improved as well. One explanation might be that scent indeed relaxes customers through a direct effect on their limbic system.

From these findings, we conclude that the nature of the shopping trip is important because shoppers may be more or less aware of the ambiguous scent presence. Since we use grocery shoppers, there was ample variety in time pressure and age.

\section{References}

Allsens. (2012). Geurmarketing in flagship store Burberry Regent Street. Retrieved 16 December, 2012

Achrol, R. S., \& Kotler, P. (2012). Frontiers of the marketing paradigm in the third millennium. Journal of the Academy of Marketing Science, 40(1), 35-52.

Aylott, Russell, \& Mitchell, Vincent-Wayne. (1999). An exploratory study of grocery shopping stressors. British Food Journal, 101(9), 683-700.

Babin, B. J., \& Attaway, J. S. (2000). Atmospheric affect as a tool for creating value and gaining share of customer. Journal of Business Research, 49(2), 91-99. 
Baker, J., Grewal, D., \& Parasuraman, A. (1994). The influence of store environment on quality inferences and store image. Journal of the academy of marketing science, 22(4), 328339.

Baker, J., Parasuraman, A., Grewal, D., \& Voss, G. B. (2002). The influence of multiple store environment cues on perceived merchandise value and patronage intentions. Journal of Marketing, 66(2), 120-141.

Baron, Robert A. (1978). Aggression and heat: The" long hot summer" revisited. Advances in environmental research, 1, 57-84.

Baron, Robert A. (1993). Affect and organizational behavior: When and why feeling good (or bad) matters. Social psychology in organizations: Advances in theory and research, 63-88.

Baron, R. A., \& Bronfen, M. I. (1994). A Whiff of Reality - Empirical-Evidence Concerning the Effects of Pleasant Fragrances on Work-Related Behavior. Journal of Applied Social Psychology, 24(13), 1179-1203.

Bitner, M. J. (1992). Servicescapes - the Impact of Physical Surroundings on Customers and Employees. Journal of Marketing, 56(2), 57-71.

Blount, S. (1995). When Social Outcomes Arent Fair - the Effect of Causal Attributions on Preferences. Organizational Behavior and Human Decision Processes, 63(2), 131-144. 
Bone, Paula Fitzgerald, \& Ellen, Pam Scholder. (1999). Scents in the marketplace: explaining a fraction of olfaction. Journal of Retailing, 75(2), 243-262.

Bradford, K. D., \& Desrochers, D. M. (2009). The Use of Scents to Influence Consumers: The Sense of Using Scents to Make Cents. Journal of Business Ethics, 90, 141-153.

Cain, W. S. (1982). Odor Identification by Males and Females - Predictions Vs Performance. Chemical Senses, 7(2), 129-142.

Castellanos, Kenia M., Hudson, Judith A., Haviland-Jones, Jeannette, \& Wilson, Patricia J. (2010). Does exposure to ambient odors influence the emotional content of memories? The American Journal of Psychology, 123(3), 269-279.

Chebat, Jean-Charles, \& Michon, Richard. (2003). Impact of ambient odors on mall shoppers' emotions, cognition, and spending: A test of competitive causal theories. Journal of Business Research, 56(7), 529-539.

Chebat, Jean-Charles, Morrin, Maureen, \& Chebat, Daniel-Robert. (2009). Does Age Attenuate the Impact of Pleasant Ambient Scent on Consumer Response? Environment and Behavior, 41(2), 258-267.

Cirrincione, A., Estes, Z., \& Carù, A. (2014). The Effect of Ambient Scent on the Experience of Art: Not as Good as It Smells. Psychology \& Marketing, 31(8), 615-627. 
Donovan, R. J., \& Rossiter, J. R. (1982). Store Atmosphere - an Environmental Psychology Approach. Journal of Retailing, 58(1), 34-57.

Donovan, R. J., Rossiter, J. R., Marcoolyn, G., \& Nesdale, A. (1994). Store Atmosphere and Purchasing Behavior. Journal of Retailing, 70(3), 283-294.

Doty, R. L., Shaman, P., Applebaum, S. L., Giberson, R., Siksorski, L., \& Rosenberg, L. (1984). Smell Identification Ability - Changes with Age. Science, 226(4681), 1441-1443.

Doucé, Lieve, \& Janssens, Wim. (2013). The Presence of a Pleasant Ambient Scent in a Fashion Store: The Moderating Role of Shopping Motivation and Affect Intensity. Environment and Behavior, 45(2), 215-238.

Doucé, L., Janssens, W., Leroi-Werelds, S., \& Streukens, S. (in press). What to diffuse in a gender-specific store? The effect of male and female perfumes on customer value and behaviour. Journal of Consumer Behaviour.

Engen, T. (1991). Odor Sensation and Memory. New York, NY: Greenwood Publishing Group.

Fiore, A. M., Yah, X. L., \& Yoh, E. (2000). Effects of a product display and environmental fragrancing on approach responses and pleasurable experiences. Psychology \& Marketing, 17(1), 27-54. 
Gardner, M. P. (1985). Mood States and Consumer-Behavior - a Critical-Review. Journal of Consumer Research, 12(3), 281-300.

Goldkuhl, L., \& Styven, M. (2007). Sensing the scent of service success. European Journal of Marketing, 41(11-12), 1297-1305.

Herrington, J Duncan, \& Capella, Louis M. (1995). Shopper reactions to perceived time pressure. International Journal of Retail \& Distribution Management, 23(12), 13-20.

Herrmann, Andreas, Zidansek, Manja, Sprott, David E., \& Spangenberg, Eric R. (2013). The Power of Simplicity: Processing Fluency and the Effects of Olfactory Cues on Retail Sales. Journal of Retailing, 89(1), 30-43.

Hirsch, A. R. (1995). Effects of Ambient Odors on Slot-Machine Usage in a Las-Vegas Casino. Psychology \& Marketing, 12(7), 585-594.

Knasko, S.C. (1989). Ambient odor and shopping behavior. Chemical Senses, 14(94), 718.

Knasko, S.C. (1992). Ambient odor's effect on creativity, mood, and perceived health. Chemical Senses, 17(1), 27-35.

Knasko, S.C. (1995). Pleasant Odors and Congruency - Effects on Approach Behavior. Chemical Senses, 20(5), 479-487. 
Krishna, Aradhna, Lwin, May O, \& Morrin, Maureen. (2010). Product scent and memory. Journal of Consumer Research, 37(1), 57-67.

Labrecque, L. I., \& Milne, G. R. (2012). Exciting red and competent blue: the importance of color in marketing. Journal of the Academy of Marketing Science, 40(5), 711-727.

Laing, David George, Doty, Richard L, \& Breipohl, Winrich. (1991). The human sense of smell: Springer.

Lawless, H.T. (1997). Tasting and smelling. In G. K. Beauchamp \& L. Bartoshuk (Eds.), Handbook of perception and cognition. San Diego, CA: Academic Press.

Lehrner, J., Marwinski, G., Lehr, S., Johren, P., \& Deecke, L. (2005). Ambient odors of orange and lavender reduce anxiety and improve mood in a dental office. Physiology \& Behavior, 86(1-2), 92-95.

Lehrner, Johann, Marwinski, G, Lehr, S, Johren, P, \& Deecke, L. (2005). Ambient odors of orange and lavender reduce anxiety and improve mood in a dental office. Physiology \& Behavior, 86(1-2), 92-95.

Lwin, M. O., \& Morrin, M. (2012). Scenting movie theatre commercials: The impact of scent and pictures on brand evaluations and ad recall. Journal of Consumer Behaviour, 11(3), 264272. 
Mattila, A. S., \& Wirtz, J. (2001). Congruency of scent and music as a driver of in-store evaluations and behavior. Journal of Retailing, 77(2), 273-289.

McCaffrey, R., Thomas, D. J., \& Kinzelman, A. O. (2009). The Effects of Lavender and Rosemary Essential Oils on Test-Taking Anxiety Among Graduate Nursing Students. Holistic Nursing Practice, 23(2), 88-93.

Madzharov, A. V., Block, L. G., \& Morrin, M. (2015). The Cool Scent of Power: Effects of Ambient Scent on Consumer Preferences and Choice Behavior. Journal of Marketing, 79(1), 83-96.

Mehrabian, Albert, \& Russell, James A. (1974). An approach to environmental psychology. Cambridge, MA: MIT Press.

Michon, R., Chebat, J. C., \& Turley, L. W. (2005). Mall atmospherics: the interaction effects of the mall environment on shopping behavior. Journal of Business Research, 58(5), 576583.

Mitchell, Deborah J, Kahn, Barbara E, \& Knasko, Susan C. (1995). There's something in the air: effects of congruent or incongruent ambient odor on consumer decision making. Journal of Consumer Research, 229-238.

Moore, D. J. (2014). Is anticipation delicious? Visceral factors as mediators of the effect of olfactory cues on purchase intentions. Journal of Business Research, 67(9), 2045-2051. 
Morrin, M., \& Ratneshwar, S. (2000). The impact of ambient scent on evaluation, attention, and memory for familiar and unfamiliar brands. Journal of Business Research, 49(2), 157 165.

Morrison, M., Gan, S., Dubelaar, C., \& Oppewal, H. (2011). In-store music and aroma influences on shopper behavior and satisfaction. Journal of Business Research, 64(6), 558564.

Nixdorf, RR, Teerling, A, \& Köster, EP. (1992). The effect of olfactory stimuli on the time spent by customers in textile-department-stores. Paper presented at the 14th AChems conference, Sarasota, USA.

Noda, M., Takai, J., \& Yoshida, T. (2007). The influence of time pressure on moodcongruent effects: Evaluating products with limited information. Journal of Applied Social Psychology, 37(2), 403-425.

Park, C. W., Iyer, E. S., \& Smith, D. C. (1989). The Effects of Situational Factors on in-Store Grocery Shopping Behavior - the Role of Store Environment and Time Available for Shopping. Journal of Consumer Research, 15(4), 422-433.

Parsons, A., \& Conroy, D. (2006). Sensory stimuli and e-tailers. Journal of Consumer Behaviour, 5(1), 69-81.

Peltier, M. (1998). Conditioning indoor environments using aroma technology. Drug \& Cosmetic Industry, 162(3), 18-20. 
Petty, Richard E, \& Cacioppo, John T. (1986). The elaboration likelihood model of persuasion. Advances in experimental social psychology, 19(1), 123-205.

Preacher, K. J., \& Hayes, A. F. (2008). Asymptotic and resampling strategies for assessing and comparing indirect effects in multiple mediator models. Behavior Research Methods, 40(3), 879-891.

Richardson, J. T. E., \& Zucco, G. M. (1989). Cognition and Olfaction - a Review. Psychological Bulletin, 105(3), 352-360.

Schifferstein, H. N. J., Talke, K. S. S., \& Oudshoorn, D. J. (2011). Can Ambient Scent Enhance the Nightlife Experience? Chemosensory Perception, 4(1-2), 55-64.

Seo, Han-Seok, Roidl, Ernst, Müller, Friedrich, \& Negoias, Simona. (2010). Odors enhance visual attention to congruent objects. Appetite, 54(3), 544-549.

Spangenberg, E. R., Crowley, A. E., \& Henderson, P. W. (1996). Improving the store environment: Do olfactory cues affect evaluations and behaviors? Journal of Marketing, 60(2), 67-80.

Spence, C., Puccinelli, N. M., Grewal, D., \& Roggeveen, A. L. (2014). Store atmospherics: A multisensory perspective. Psychology \& Marketing, 31(7), 472-488. 
Spies, K., Hesse, F., \& Loesch, K. (1997). Store atmosphere, mood and purchasing behavior. International Journal of Research in Marketing, 14(1), 1-17.

Steenkamp, Jan-Benedict EM, \& Van Trijp, Hans. (1991). The use of LISREL in validating marketing constructs. International Journal of Research in Marketing, 8(4), 283-299.

Stöhr, A. (1998). Air-Design als Erfolgsfaktor im Handel. Wiesbaden: Deutscher Universitäts Verlag.

Teerling, A., Nixdorf, R.R., \& Köster, E.P. (1992). The effect of ambient odours on shopping behavior. Chemical Senses, 17, 886.

Teller, Christoph, \& Dennis, Charles. (2011). The effect of ambient scent on consumers' perception, emotions and behaviour: A critical review. Journal of Marketing Management, 28(1-2), 14-36.

Turley, Louis W., \& Chebat, Jean-Charles. (2002). Linking retail strategy, atmospheric design and shopping behaviour. Journal of Marketing Management, 18(1-2), 125-144.

Turley, L. W., \& Milliman, R. E. (2000). Atmospheric effects on shopping behavior: A review of the experimental evidence. Journal of Business Research, 49(2), 193-211.

Vinitzky, G., \& Mazursky, D. (2011). The effects of cognitive thinking style and ambient scent on online consumer approach behavior, experience approach behavior, and search motivation. Psychology \& Marketing, 28(5), 496-519. 
Zeithaml, V. A., \& Bitner, M. J. (1996). Services Marketing. Boston: McGraw-Hill. 


\section{Multi Item Scales Used in the Study}

\section{Affect (7-point scales)}
1. Unhappy/ happy
2. Unsatisfied/satisfied
3. Annoyed/ pleased
4. Stimulated/ relaxed
5. Calm/ excited
6. Unaroused/ aroused
7. Controlled/ controlling
8. Guided/ autonomous

\section{Evaluation of the store (10-point scales)}

1. The general store (bad/ good)

2. The quality of the store (low/ high)

3. The satisfaction with the store (low/ high)

III. Evaluation of the store environment (7-point scales)
1. Unpleasant/ pleasant
2. Untidy/tidy
3. Outdated/ modern
4. Uncomfortable/ comfortable
5. Closed/ open

IV. Evaluation of the merchandize (7-point scales)

1. The quality of the bakery products (low/ high)

2. The quality of the fruit and vegetables (low/ high)

3. The quality of the meat and meat products (low/ high) 
Figure 1 Model

Time pressure (and personal characteristics of shoppers)

Treatments

No scent

Scent at threshold (50\%)

Scent at suprathreshold (70\%)

$\downarrow$

Evaluation

Overall store evaluation

Store environment

Store merchandize

Approach behavior

Objective shopping time

Subjective shopping time

Unplanned purchases

Store level sales 


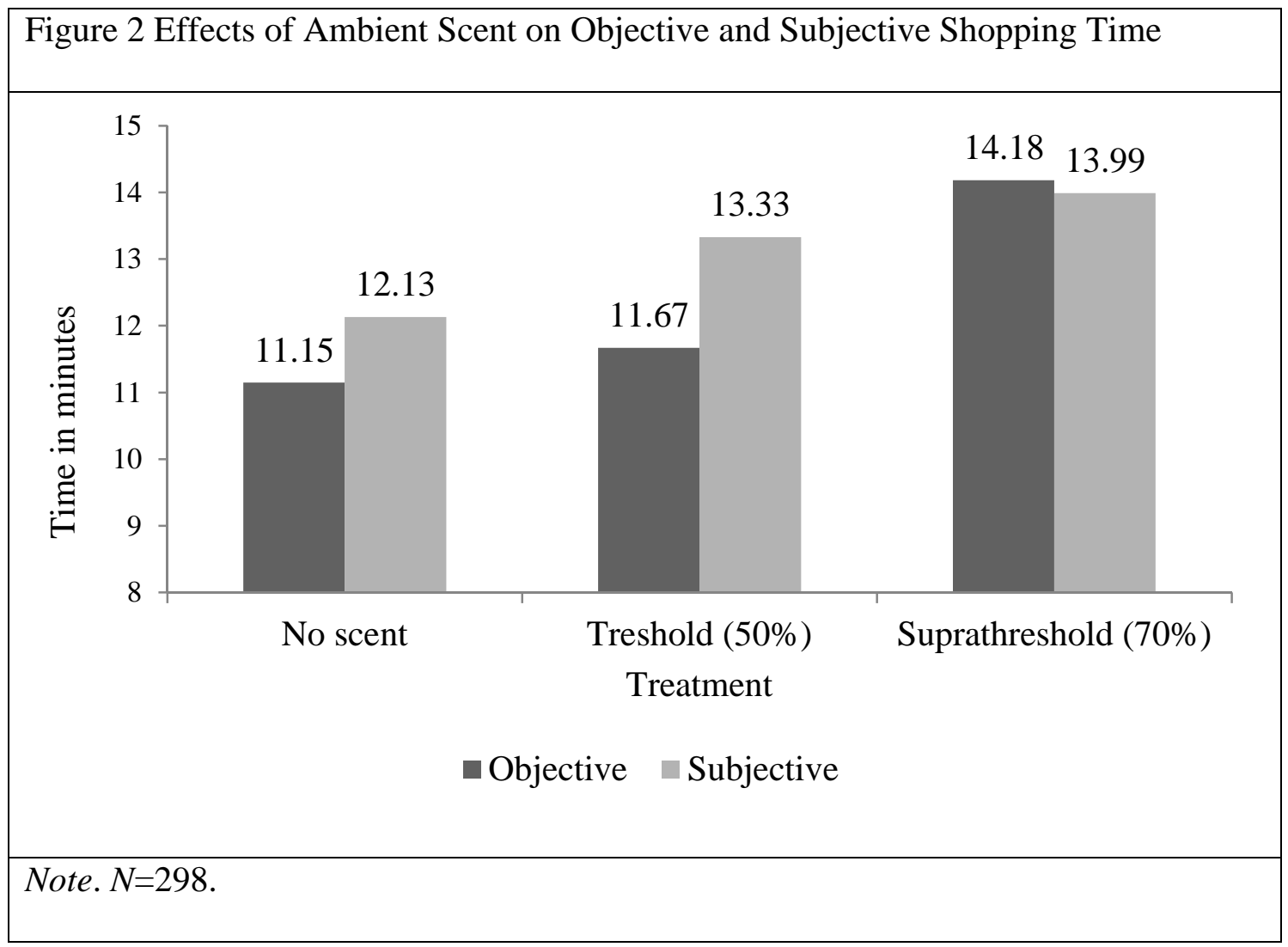




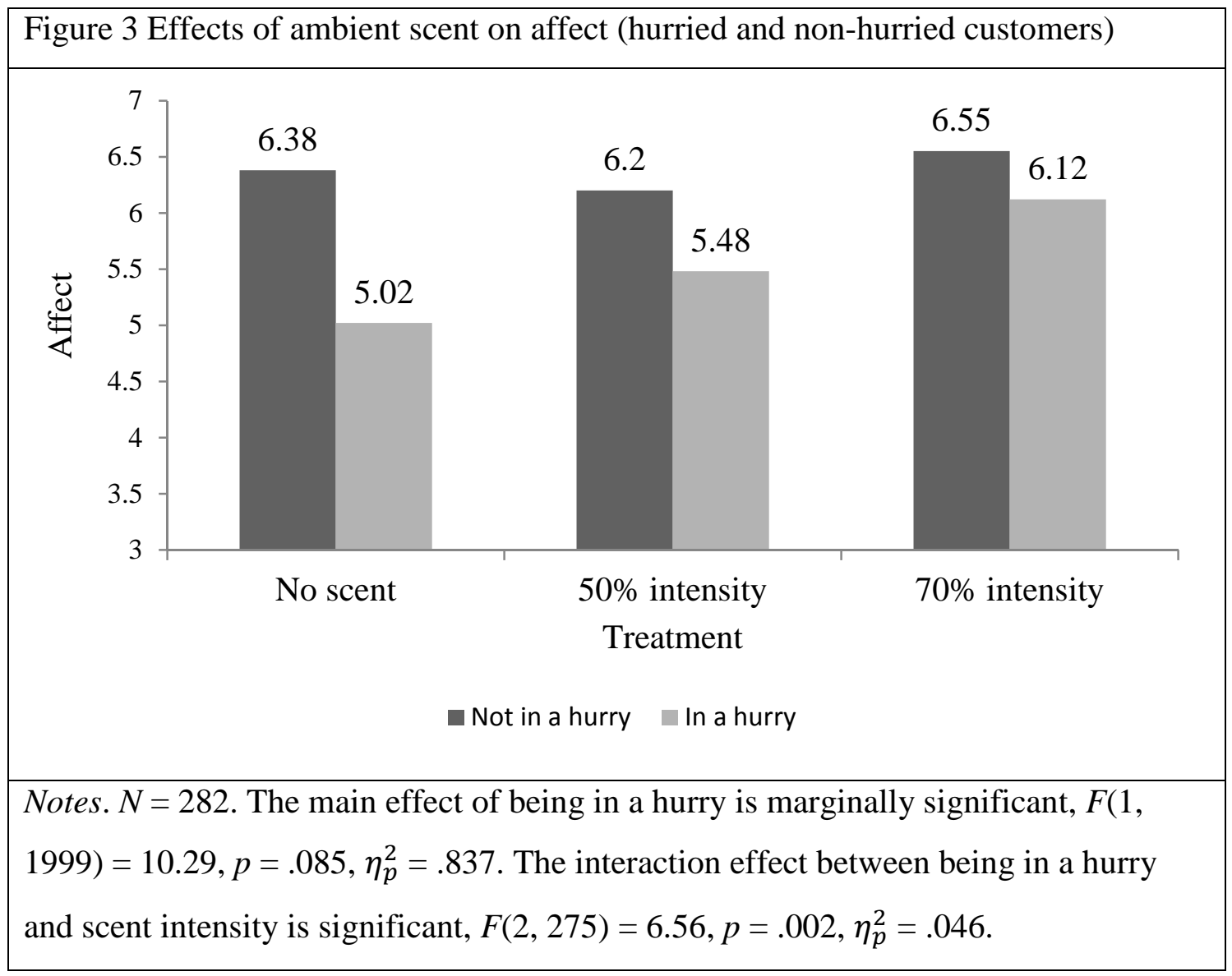




\section{TABLES}

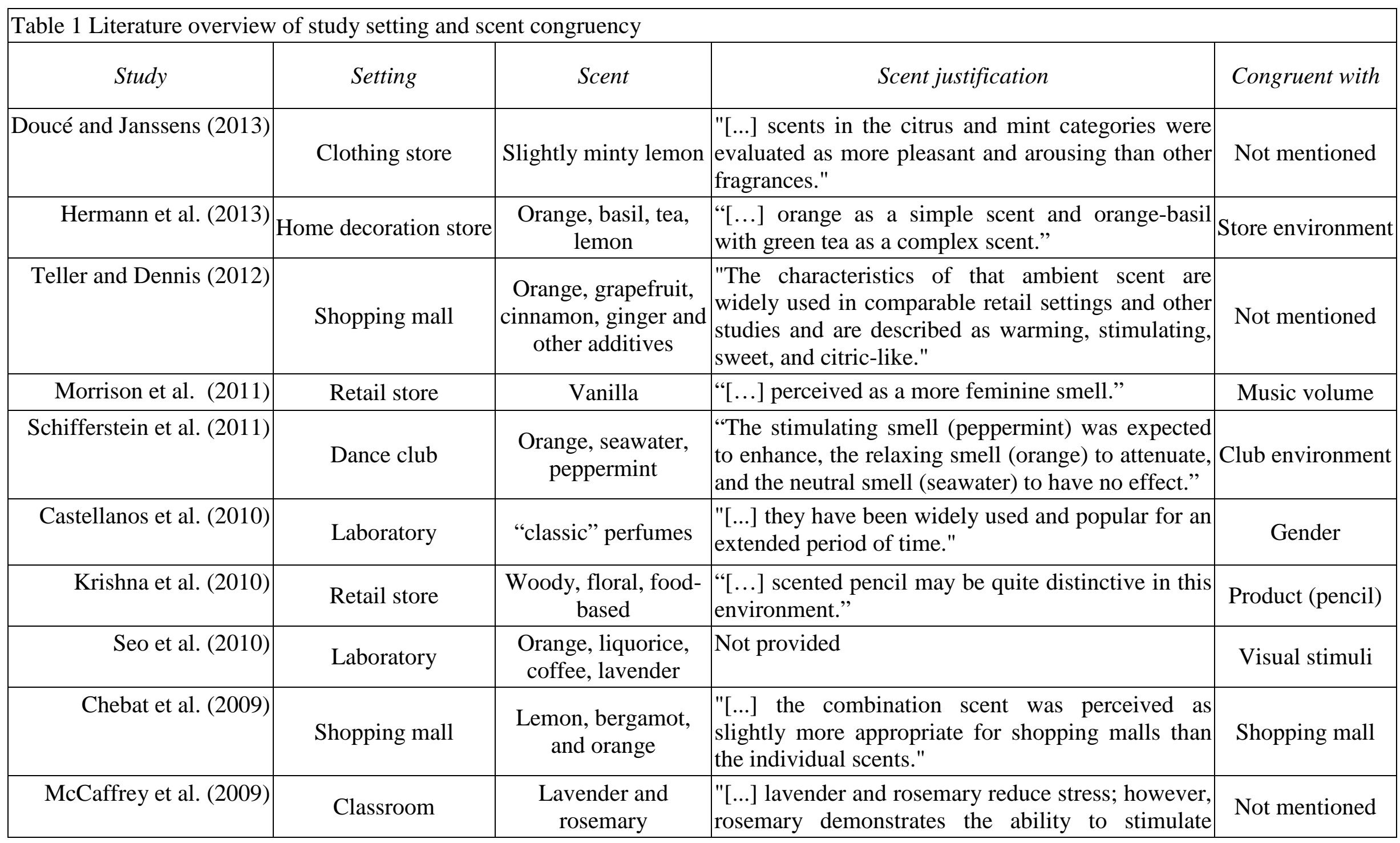




\begin{tabular}{|c|c|c|c|c|}
\hline & & & cognition and memory" & \\
\hline Spangenberg et al. (2006) & Clothing store & Natural essential oils & $\begin{array}{l}\text { "[...] be gender-oriented. }[\ldots] \text { required the scents to } \\
\text { be currently in use by retailers." }\end{array}$ & Gender \\
\hline Mattila and Wirtz (2001) & Gift store & Lavender, grapefruit & $\begin{array}{l}\text { "[...] based on two criteria: the mood effects and } \\
\text { cautionary effects." }\end{array}$ & Music tempo \\
\hline Mitchell et al. (1995) & Laboratory & Floral, chocolate & $\begin{array}{l}\text { "[...] were fully crossed with two product choice } \\
\text { conditions (chocolate assortments, flower } \\
\text { arrangements)" }\end{array}$ & Product class \\
\hline
\end{tabular}




\begin{tabular}{|c|c|c|c|c|c|}
\hline \multicolumn{6}{|c|}{ Table 2 Other treatment effects of ambient scent } \\
\hline \multirow[b]{2}{*}{ Dependent variable } & \multicolumn{3}{|c|}{ Scent intensity } & \multirow{2}{*}{$F(p)$} & \\
\hline & No scent & $50 \%$ & $70 \%$ & & \\
\hline Affect & 5.86 & 5.90 & 6.33 & $7.16(.001)$ & \\
\hline Evaluation store environment & 5.80 & 5.74 & 6.03 & $2.86(.059)$ & \\
\hline Evaluation store merchandize & 5.73 & 5.92 & 6.07 & $2.85(.059)$ & \\
\hline Overall evaluation store & 7.85 & 7.95 & 8.07 & $1.57(.201)$ & \\
\hline Unplanned purchases & 0.33 & 0.30 & 0.43 & $4.25(.060)$ & \\
\hline \multicolumn{6}{|c|}{$\begin{array}{l}\text { Notes. Marginal means are provided except for unplanned purchases. The } p \text {-values are in } \\
\text { parentheses. The figures in the last column represent effect size. The } \chi^{2} \text { test is one-sided. The } \\
\text { logarithm of shopping time (objective and subjective) is used to test for significant differences. }\end{array}$} \\
\hline
\end{tabular}




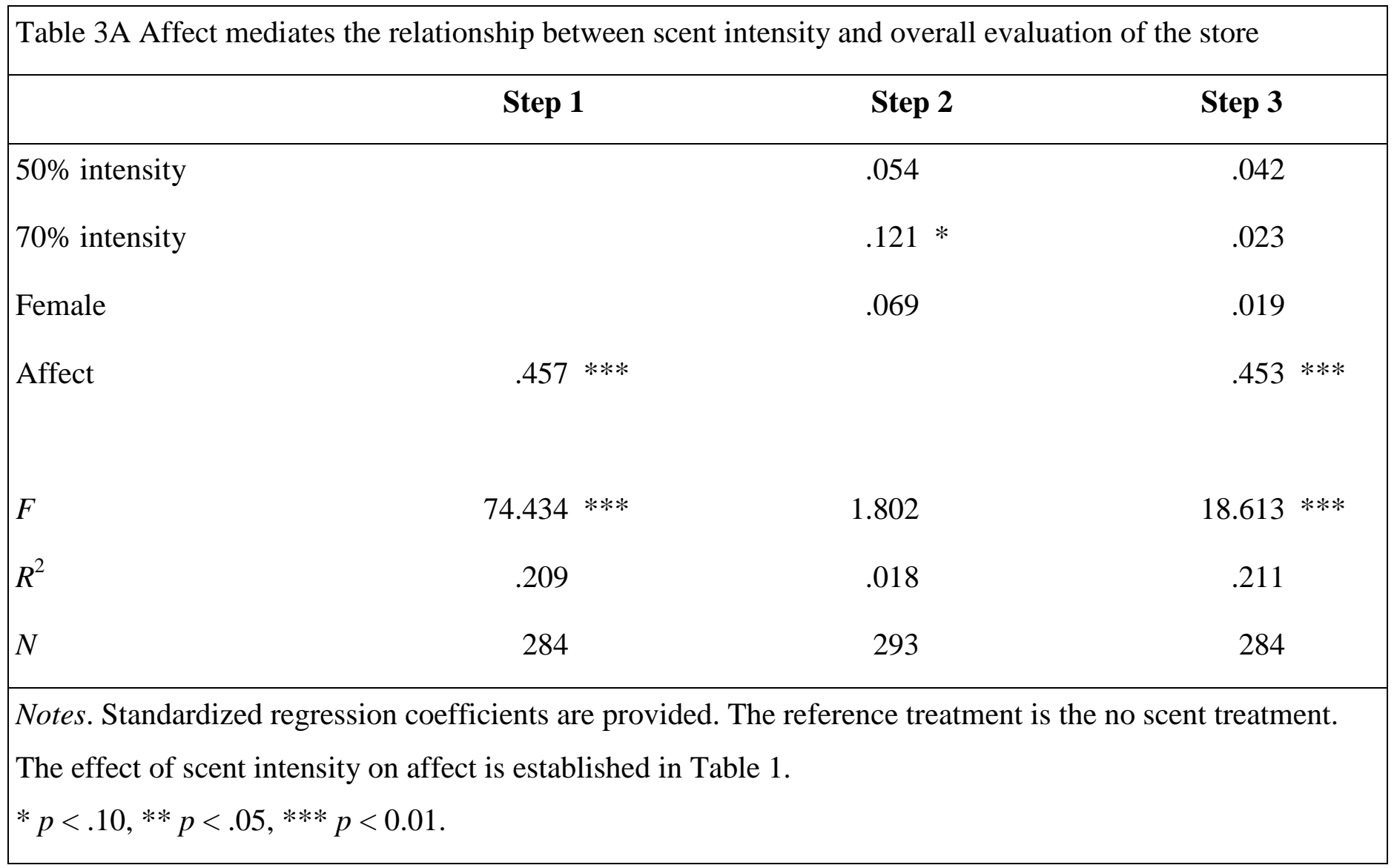




\begin{tabular}{|c|c|c|c|}
\hline & Step 1 & Step 2 & Step 3 \\
\hline $50 \%$ intensity & & .057 & .034 \\
\hline $70 \%$ intensity & & $.255 * * *$ & $.215 * *$ \\
\hline Female & & $.098 *$ & .092 \\
\hline Affect & $.142 * * *$ & & .080 \\
\hline$F$ & $5.934 * *$ & 7.585 & $5.493 * * *$ \\
\hline$R^{2}$ & .020 & .071 & .072 \\
\hline$N$ & 290 & 302 & 290 \\
\hline \multicolumn{4}{|c|}{$\begin{array}{l}\text { Notes. Standardized regression coefficients are provided. The logarithm of shopping time is used. The } \\
\text { reference treatment is the no scent treatment. } \\
* p<.10, * * p<.05, * * * p<0.01 \text {. }\end{array}$} \\
\hline
\end{tabular}




\begin{tabular}{|c|c|c|c|}
\hline \multicolumn{4}{|c|}{ Table 4 Summary overview of mediation analyses } \\
\hline \multirow[b]{2}{*}{ Dependent variable } & \multicolumn{3}{|c|}{ Independent variables } \\
\hline & Affect $\rightarrow$ & $\begin{array}{c}70 \% \rightarrow \\
\text { (no mediator) }\end{array}$ & $\begin{array}{c}70 \% \rightarrow \\
\text { (with affect as mediator) }\end{array}$ \\
\hline Overall evaluation store & $.457(.000)$ & $.121(.078)$ & $.023(.719)$ \\
\hline Evaluation store environment & $.598(.000)$ & $.119(.073)$ & $.028(.799)$ \\
\hline Evaluation store merchandize & $.545(.000)$ & $.160(.018)$ & $.048(.418)$ \\
\hline Objective shopping time & $.142(.015)$ & $.255(.000)$ & $.215(.002)$ \\
\hline Subjective shopping time & $.158(.008)$ & $.105(.168)$ & $.047(.501)$ \\
\hline Unplanned purchases & $-.260(.732)$ & $.470(.118)$ & $.537(.085)$ \\
\hline \multicolumn{4}{|c|}{$\begin{array}{l}\text { Notes. Standardized regression coefficients are provided except for unplanned purchases (logistic regression). The mediation analysis for overall } \\
\text { evaluation store and objective shopping time corresponds to Table } 3.1 \text { and } 3.2 \text { respectively. The same procedure is used for the other dependent } \\
\text { variables. The logarithm of shopping time is used. The } p \text {-values are in parentheses. }\end{array}$} \\
\hline
\end{tabular}

